Proceedings

\title{
Concrete Column Demolding Time Optimization Based on Reflection Wave Measurements ${ }^{\dagger}$
}

\author{
Nicolas Ospitia ${ }^{1}$, Rami Jaramani ${ }^{1}$, Olivier Remy ${ }^{1,2}$ and Dimitrios G. Aggelis 1,* \\ 1 Department Mechanics of Materials and Constructions, Vrije Universiteit Brussel (VUB), Pleinlaan 2, 1050 \\ Brussels, Belgium; nicolas.ospitia.patino@vub.be (N.O.); Rami.Jaramani@ulb.be (R.J.); \\ o.remy@plakagroup.be (O.R.) \\ 2 Plaka a CRH Company, Ternat 1740, Belgium \\ * Correspondence: daggelis@vub.ac.be \\ + Presented at 1st International Electronic Conference on Applied Sciences, 10-30 November 2020; Available \\ online: https://asec2020.sciforum.net/.
}

Published: 10 November 2020

\begin{abstract}
In the present study, a combination of experimental techniques is studied to monitor the state of fresh concrete inside composite formworks. The aim is to acquire information about the stiffness of the concrete for which safe removal of the formworks can be done. Determining early age properties of concrete is important not only for ensuring safety on construction sites but also for presenting economic advantages. Removal of formworks in the appropriate time avoids delays in the construction works and allows the reuse of formworks in an efficient manner and thus reduce the associated cost. Experimental monitoring was complemented by numerical simulations to clearly investigate the ultrasonic propagation in fresh concrete and how the hydration process affects this propagation. The experiments showed promising results in monitoring the increase of stiffness in the concrete inside the formwork through an one-sided measurement. Strain measurements carried out at different heights of a cylindrical formwork gave information about the pressure distribution on the formwork to ensure limit stress values are not reached. In addition, monitoring the strain variation confirmed the trends of increase in the stiffness by giving indications about the shrinkage and thermal expansion of concrete.
\end{abstract}

Keywords: wave propagation; reflection coefficient; formwork; concrete; stiffness; setting

Publisher's Note: MDPI stays neutral with regard to jurisdictional claims in published maps and institutional affiliations.

(C) 2020 by the authors. Submitted for possible open access publication under the terms and conditions of the Creative Commons Attribution (CC BY) license (http://creativecommons.org/licenses/by/4.0/). 